\title{
CULTURAL AND SUB-CULTURAL COMPARISONS IN PREFERENCES FOR NATURAL SETTINGS
}

\author{
RACHEL KAPLAN ${ }^{1}$ and EUGENE J. HERBERT ${ }^{2}$ \\ ${ }^{1}$ University of Michigan, Ann Arbor, MI 48109 (U.S.A.) \\ ${ }^{2}$ Siteplan, Cairns, Qld. 4871 (Australia)
}

(Accepted for publication 1 August 1986)

\section{ABSTRACT \\ Kaplan, R. and Herbert, E.J., 1987. Cultural and sub-cultural comparisons in preferences for natural settings. Landscape Urban Plann., 14: 281-293.}

Although studies of preferences for natural environments across cultures have tended to find rather high agreement, most studies have concentrated on correlational findings. Analyses of actual preference levels and of perceptual categories yield a more complete picture. Western Australian and American student preference ratings of scenes of the Western Australian landscape provided an opportunity to examine cross-cultural comparisons for both preference and perception. The inclusion of a third sample, however, makes evident even greater sub-cultural differences. A Western Australian group sharing an interest in flora and conservation showed distinctly different preference patterns to the Australian students. The study demonstrates the effect of different aspects of familiarity on environmental preference. Furthermore, preference ratings may serve as an effective participation tool to identify differences among interest groups.

\section{INTRODUCTION}

While preferences for natural settings are remarkably consistent, some variation occurs across people of different ages, ethnic groups, and areas of expertise. Similarly, cross-cultural preferences have a high degree of homogeneity, but with some differences. The reasons for the differences are not yet clear. Familiarity is a likely factor, but it does not account for all discrepancies.
Generally the reportcd results are based on correlations between preference ratings which may be relatively high, but do not tell all of the story. Rating magnitudes may vary substantially, and this may help to explain preference patterns. Furthermore, the focus on preferences per se may be insufficient. Even with relatively similar preference ratings, therc may be substantial group differences in environmental perception. Unfortunately people may not be able to verbalize the perceptual categories 
being used, but statistical procedures enable the extraction of perceptual categories from preference data (Kaplan, 1985). Such procedures permit comparisons of how different groups categorize environments and enhance the analysis of differences in preference. As well as scene-by-scene comparisons, preference differences can be examined for groupings of scenes.

The present study entails comparisons of cultural and sub-cultural factors in both preference and perception. Scenes of Western Australian forests and open areas were viewed by individuals differing in familiarity with such settings. College students at an American and a Western Australian university served as participants. These two student samples, comparable in age and education level, permit examination of cultural influence. A second group of Western Australian residents provide a further basis for comparison. These belong to a wildflower society, a group interested in local plants and conservation. They are both older than the student samples and more experienced with the settings considered. Comparison of the two Australian samples provides insight into sub-cultural influences, especially with respect to interest and expertise.

Ideally, there would be further comparison groups to separate age and expertise influences and to examine other factors. Nonetheless, the availability of data from these three groups makes possible the separation of cultural and other influences and permits a richer examination of the role of familiarity in preference.

\section{REVIEW OF THE LITERATURE}

The literature on cross-cultural comparison in preferences for natural environments shows relatively high agreement when cultures are relatively similar (Zube, 1984). Zube and Mills (1976), for example, reported correlations ranging between 0.76 and 0.89 among two Australian samples (seasonal and year-round residents) and American landscape architec- ture students, using photographs of Australian landscapes. Zube and Pitt's (1981) comparisons among Yugoslavian students, Italian Americans, and various other American groups show similar high correlation coefficients for scenes of northeastern American landscapes. Shafer and Tooby (1973) also reported consistent preference in their comparison of Scottish and American samples, and Ulrich (1983) found consistent patterns between Swedes and Americans.

By contrast, with relatively dissimilar cultural groups the preferences are distinctly less comparable. Sonnenfeld (1967) found strong differences in preference among native and non-native Arctic residents. Zube and Pitt (1981) reported relatively lower correlations between scenic quality ratings on the part of West Indians and American (as well as Yugoslavian) samples viewing scenes of the Virgin Islands.

Even within the same culture, preferences are not always consistent. In particular, some studies have shown age-related discrepancies in preferences, with adolescents especially dissimilar from other age groups (Balling and Falk, 1982; Zube et al., 1983). A few studies reported differences in natural environment preferences related to ethnic and/or urban background variables (Zube and Pitt, 1981; Schroeder, 1983; Kaplan and Talbot, 1987).

While high agreement has been found among observers (Coughlin and Goldstein, 1970; Zube et al., 1975; Daniel and Boster, 1976). substantial differences may occur among members of the same culture, those in roughly the same age range, and those sharing other background characteristics. These differences are attributable to professional background and/or vocational interests related to the environment. Buhyoff et al. (1978), for example, reported that landscape architects could predict quite accurately the preferences of "client" groups, based on verbal descriptions. However, the correlation between the preferences of the professional and lay groups was close to 
zero. Daniel and Boster (1976) have shown distinctly different preference patterns on the part of conservation groups and university students as opposed to groups interested in cattle or rangeland. Other studies have also shown that knowledge or familiarity affects assessment ratings (e.g., Kaplan, 1973; Gallagher, 1977; Anderson, 1978; Buhyoff et al., 1979; Hammitt, 1979).

Studies dealing with group comparisons have largely explored preferences or scenic quality ratings, and have relied on correlations among preference ratings to indicate consistency. A fuller understanding of this topic requires an examination of both preferences and perception. Environmental experience may be different for diverse groups, even though they have similar preferences for specific settings. Experience of the environment may have as great a bearing on its management as does preference perse.

The study reported here thus examines both preferences and perceptions of the same environment by three groups. Two groups share a cultural perspective and are relatively familiar with the local landscape; the third group represents a different culture but is comparable in age and educational status with one of the other groups.

\section{METHODS}

\section{Participants}

Both student samples were enrolled in introductory psychology courses at their respective universities and participation in the study fulfilled a course requirement. The American sample consisted of 145 students at the University of Michigan, and the Australian sample consisted of 120 students at the University of Western Australia.

A group of 74 members of the Wildflower Society of Western Australia participated in the study at one of their regular meetings. This group has a common botanic interest in nature and a concern for conservation.

While the two student groups are of comparable age, there is no assumption of educational equivalence. However, both student groups are morc educated than the general population in their respective countries. In both cases, introductory psychology courses attract a broad range of college students who are not necessarily interested in further study in this field. The educational levels of the Wildflower Society members is not known, but is unlikely to be homogencous. In age too they cover a wider spectrum than the student groups.

\section{Procedure}

The 60 color slides sampled the five landscape types comprising the northern Jarrah forest of Western Australia (escarpment, uplands, valleys, plantations, eastern woodlands). The scencs include various specics of eucalypt trees both in areas used for timber production and as part of a reserve. Jarrah (Eucalyptus marginata) tends to dominate dry upland areas. Scenes were projected for $10 \mathrm{~s}$ and participants were asked to rate their liking of each slide using a 5 -point scale $(5=$ very much). With the student samples, the slides were shown in one of two orders using a randomized sequence with stratification of the five landscape types. (Since the Wildflower Society members were gathered for a meeting, only one presentation order could be used.)

The rating sheets provided for participants werc marked for 70 slides to avoid anticipation of the end of the task. Participants were shown the first 10 slides before beginning the rating task to provide a sense of the range of scenes.

\section{RESULTS}

Scene preference

The preference ratings showed surprisingly high agreement across samples. The 
correlations of the 60 mean slide ratings were 0.84 between the two student samples, 0.81 between the two Australian samples, and 0.65 between the Wildflower Society and the American sample.

The most preferred scenes for each sample tended to have a mix of water and mature forest with some topographic variation. Figure 1, upper left, shows one of the two scenes most favored by each sample. In general, these were the more lush as opposed to arid scenes. The least favored scenes also showed strong agreement across the three samples. The lower left scene in Fig. 5, showing a bauxite mining site prior to complete rehabilitation, received mean ratings of 1.5 from each sample, by far the lowest preference for the set of slides.

The high correlations between samples as well as the consistencies in some of the mostand least-liked scenes contrast with strong differences among the groups. On the whole, Australians rated the scenes higher than the Americans. For the two student samples, the mean preferences for the 60 slides were 3.11 and 3.28 . For 28 of the scenes differences in preference were significant at $P<0.05$, and for 8 of these the difference was greater than a half scale point (0.5). While most of the significant differences were in the direction of Australian preference, there were four scenes which the Americans preferred. Two of these were vistas (one with a river dominating the scene) which might have been taken in many parts of the United States. The other two, with a significant but smaller difference in preference, showed a palm tree in one instance and bare trees in the other. Since bare trees are more likely to reflect disease than season in the Western Australian context, this difference is understandable. The palm tree was presumably more familiar to the American sample than the predominantly grey/green eucalypts in most of the scenes.

The mean preference for the 60 slides for the Wildflower Society group was 3.32 (essentially the same as the 3.28 for the Australian student sample). However, these two samples differed in their preferences for many scenes. In 22 cases the Wildflower Society group preference was significantly higher than that of the Australian students (with 10 of these scenes reflecting more than 0.5 difference in rating). In 11 cases the preference was in the opposite direction (with five of these reflecting differences of 0.5 or greater ). Thus, in over half the cases - and in more instances than for the two student samples - the two Australian samples differed markedly in their preference ratings.

The most consistent factor in differences in preference between the two Australian samples related to the issue of use of native plants. Pines and pine plantations have been the source of considerable local debate, with some vocal citizens resenting the introduction of exotic species. The Wildflower Society members can be expected to be sensitive to this issue and to prefer virgin forests and scenes reflecting more typical native vegetative associations. The Australian students, by contrast, showed no disfavor of pines or of farmland or of other less pristine indigenous bush. These strong differences suggest that familiarity can take several forms. Greater knowledge and concern for the types of species are evident in the preference differences.

\section{Perceptual differences}

The preference differences are based on analyses of the magnitudes of the ratings. Analyzing the relationships among the ratings permits a different understanding of the results. While preference magnitudes provide some insight into differences among these groups, they do not reflect differences in the underlying categorization of the stimuli. Examination of the patterns among the ratings permits analysis of such common groupings or themes in the way the scenes are perceived. (The words "dimension", "grouping", "category" and "set" are used interchangeably here to refer to the "factors" extracted from the non-metric 
Preference means for each sample for categories derived from non-metric factor analysis

\begin{tabular}{lllrr}
\hline & $\begin{array}{l}\text { American } \\
\text { students }\end{array}$ & $\begin{array}{l}\text { Australian } \\
\text { students }\end{array}$ & $\begin{array}{l}\text { Wildflower } \\
\text { Society }\end{array}$ & $F$ \\
\hline American-based categories & & & & \\
Open woodland/field & 2.64 & 2.94 & 2.96 & 11.73 \\
Rough-textured, arid wooded & 2.67 & 2.74 & 3.20 & 15.13 \\
Open, smooth texture & 2.90 & 2.95 & 2.86 & 0.0001 \\
Vista, not heavily wooded & 3.57 & 3.34 & 3.13 & 0.0001 \\
Forest and forest vista & 3.88 & 4.00 & 3.97 & NS \\
Australian-student-based categories & & & & 0.98 \\
Arid, open, coarse texture & 2.44 & 2.61 & 2.89 & 0.0001 \\
Manipulated, open, spacious & 3.13 & 3.08 & 3.85 & 0.005 \\
Trees in forest & 3.28 & 3.57 & 3.71 & 12.61 \\
\hline
\end{tabular}

factor analysis.) Both non-metric factor analysis (Smallest Space Analysis III (Lingoes, 1972)) and ICLUST Hierarchical Cluster Analysis.) (Kulik et al., 1970) were used for this analysis. One set of analyses was conducted using American student ratings. While it is desirable to have as large a sample as possible for these procedures, only Australian student ratings were used in the second analysis. The differences in preferences between the two Australian samples were large enough to make it inadvisable to combine the two sets of data. At the same time, the sample size for the Wildflower Society group was clearly too small for such procedures. (The use of factor analysis is recommended if there are at least five times the number of observations as variables included in the analysis. It is not clear whether the same precaution is necessary for non-metric procedures which do not rely on the actual magnitude of the correlations for further steps in the algorithm. Nonetheless, the analyses discussed here do not meet this criterion and the results should, therefore, be viewed with the same caution that is due any empirical work carried out on a limited basis. )

Results of the SSA-III analysis using the American sample preference ratings yielded five categories (using a criterion of loadings greater than or equal to 0.40 , omitting scenes that load at this level on more than one cate- gory and using only categories with four or more scenes). For the Australian student sample, three such groupings emerged. Table I includes the mean preference rating for each of the categories and a brief description of each.

\section{American-based categories}

The categorization based on the preference ratings by the American sample showed greater differentiation among landscapes. Of the five resulting categories, the most preferred consisted of 12 scenes of forests (top row of Fig. 1 ), including vistas of such forests. The forests varied in density and with respect to species. Some scenes were along rivers and some included rock outcroppings. The mean preference for this grouping, the highest for each sample, was between 3.9 and 4.0.

Two other categories were also of forested landscapes. One of these consisted of 15 relatively open woodlands and fields (Fig. 2) while the other consisted of five relatively arid areas where the tree textures were coarser (Fig. 3). The differences in preferences between these two categories were particularly interesting. For the American sample the two groupings did not differ in preference, but were perceptually distinct (as evidenced by their forming separate groupings in the analysis). For the two Australian samples the preferences for the two groupings went in opposite directions. The 

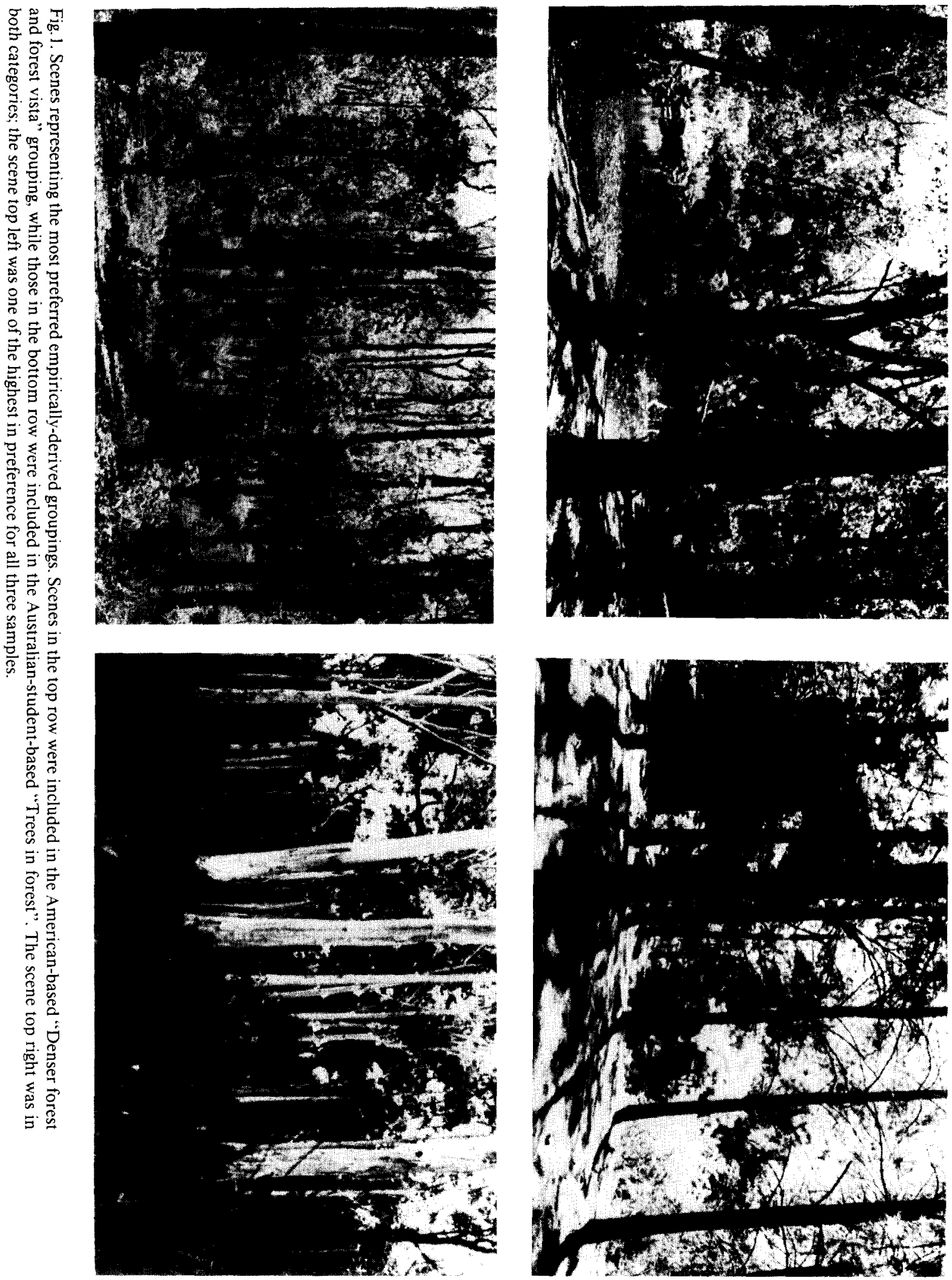


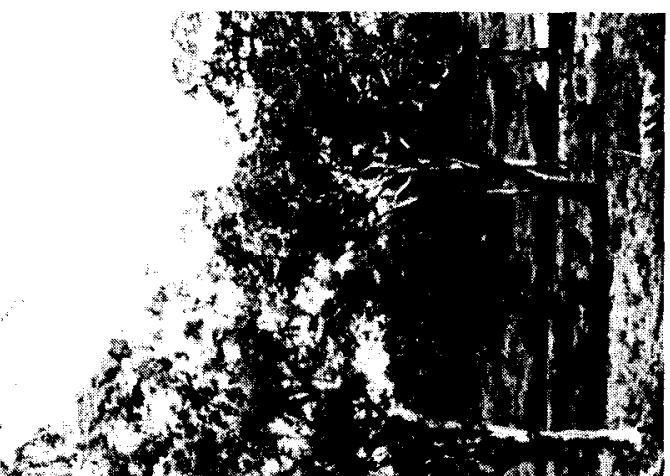

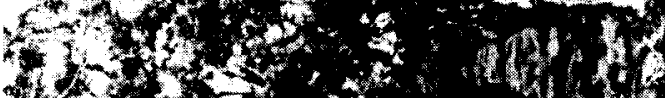

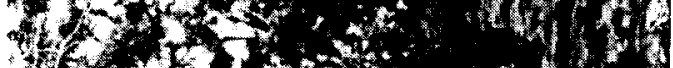

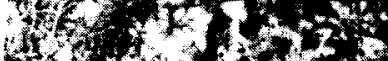
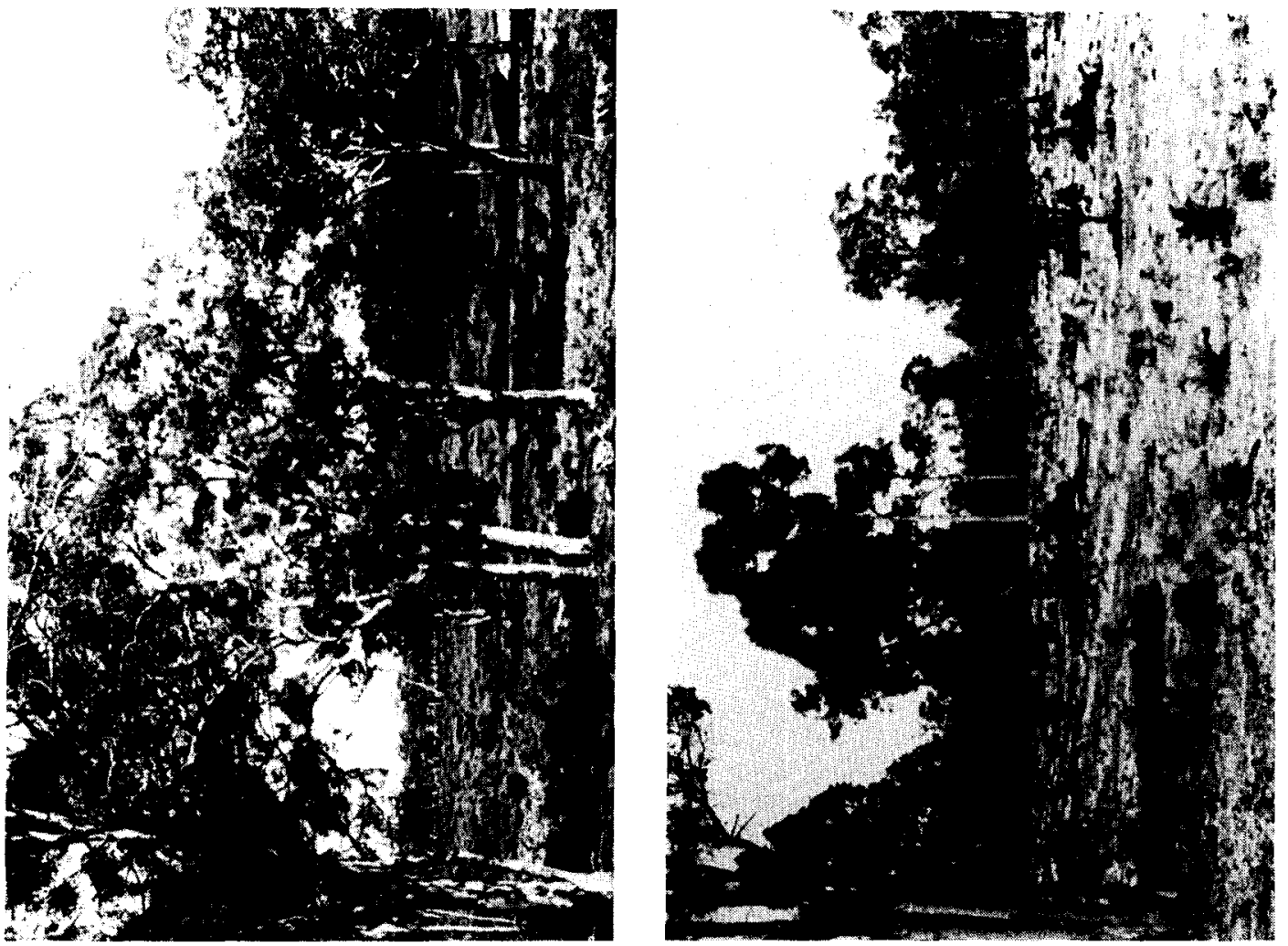

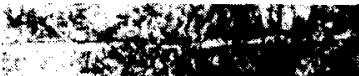

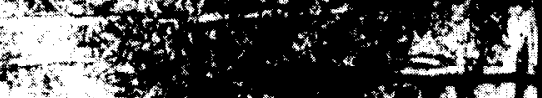

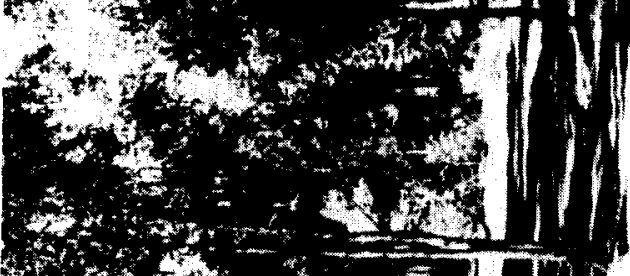

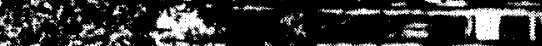

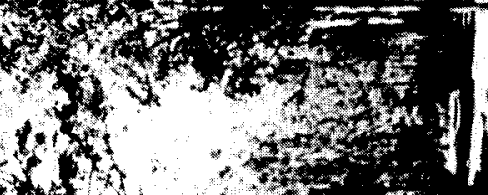
$x+1, x$

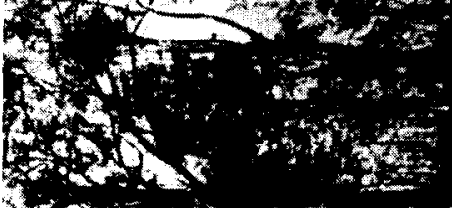

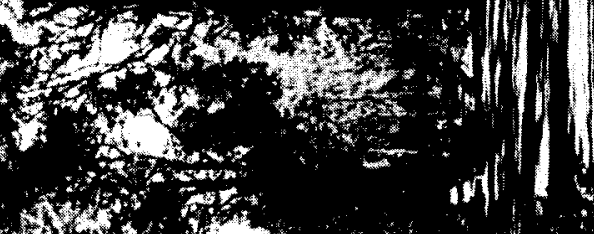
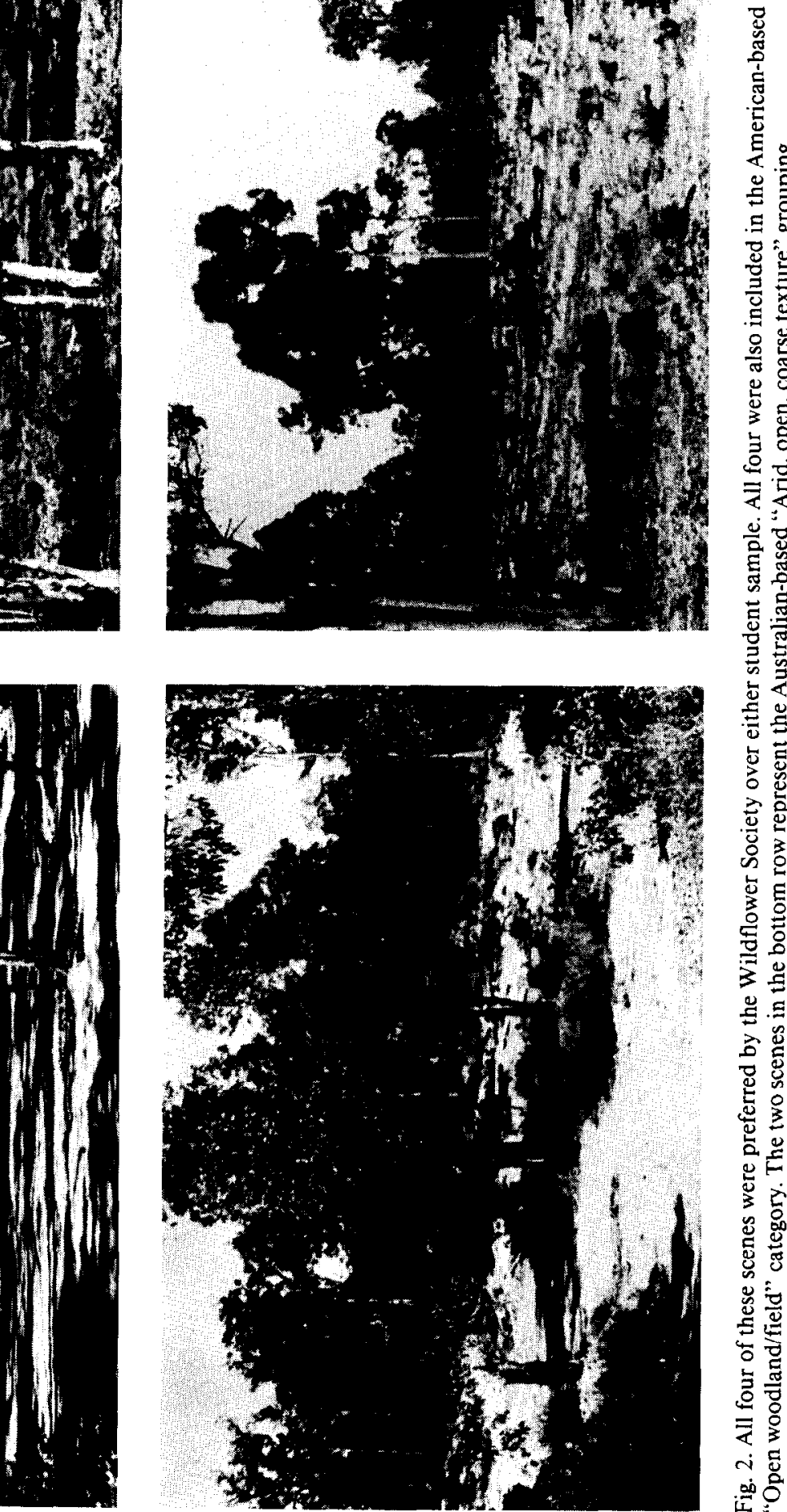

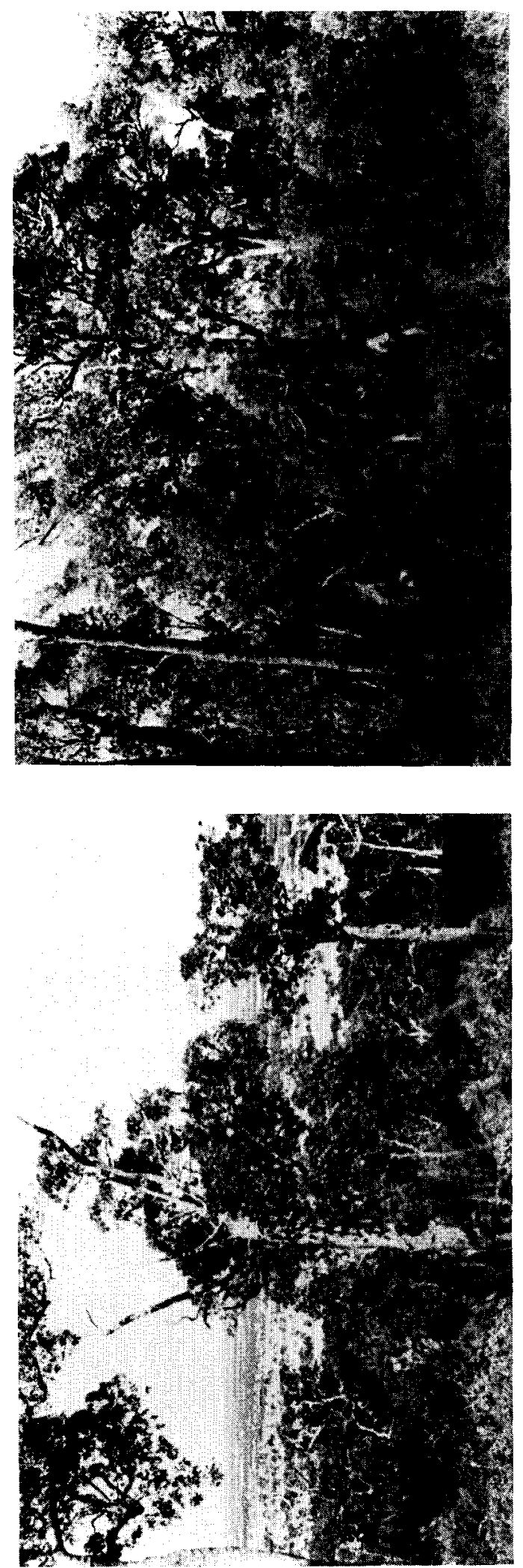
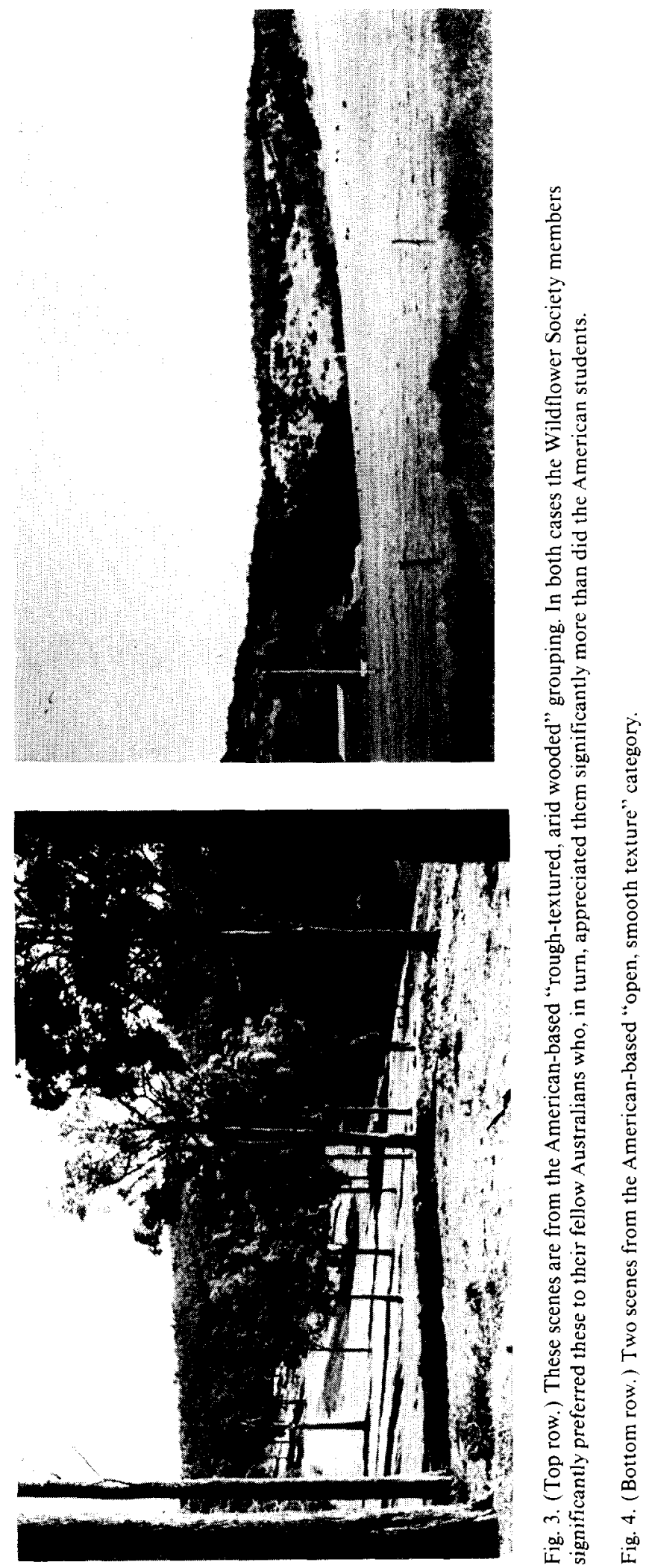

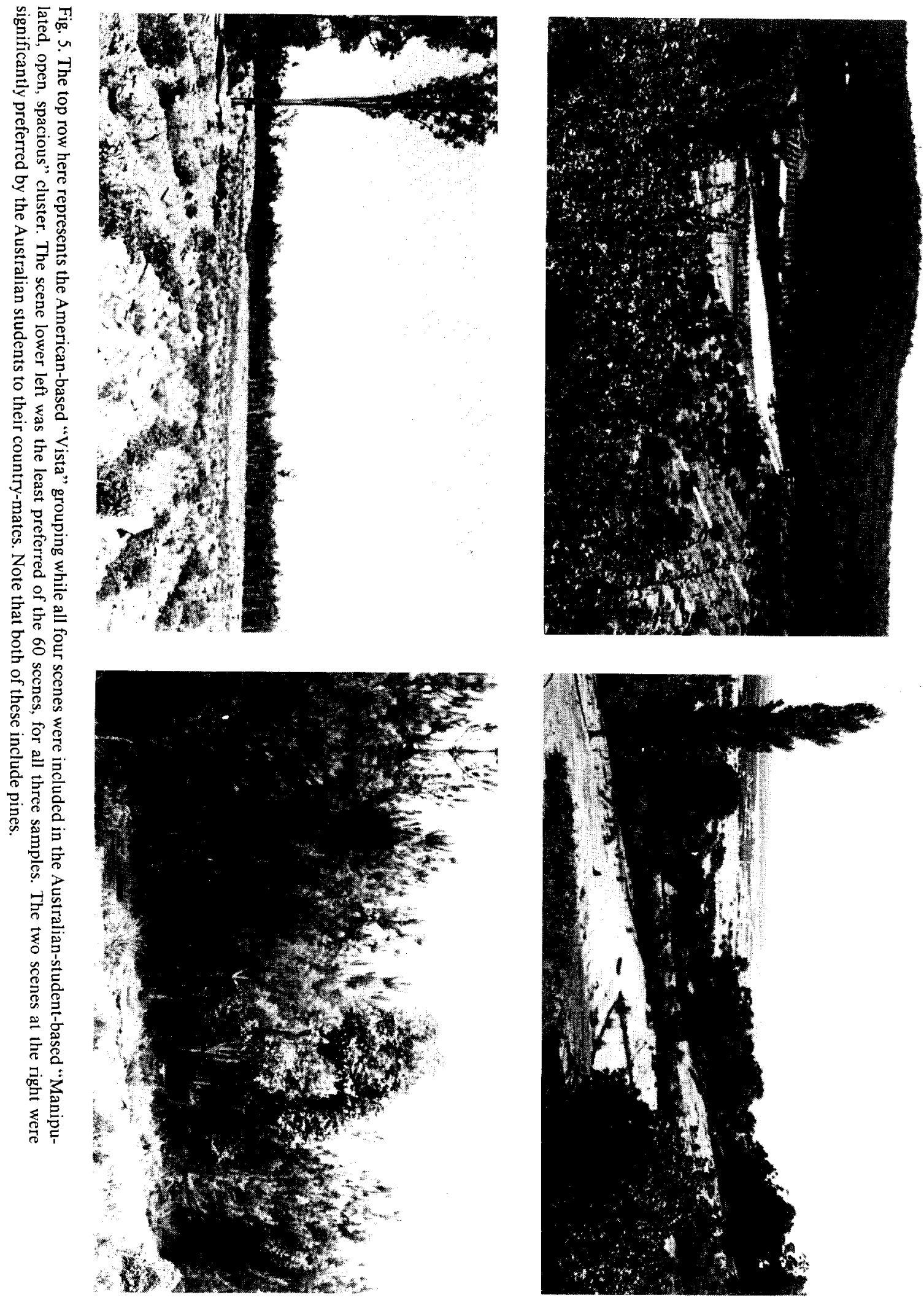
TABLE II

Correspondence between the two sets of categories

\begin{tabular}{lllll}
\hline & $\begin{array}{l}\text { Number of } \\
\text { scenes }\end{array}$ & \multicolumn{2}{l}{ Australian-student-based categories } \\
\cline { 3 - 5 } & & $\begin{array}{l}\text { Arid, open } \\
\text { coarse texture }\end{array}$ & $\begin{array}{l}\text { Manipulated } \\
\text { open, spacious }\end{array}$ & $\begin{array}{l}\text { Trees in } \\
\text { forest }\end{array}$ \\
\hline Number of scenes & 10 & 12 & 19 \\
American-based categories & 5 & 7 & 2 & 1 \\
$\begin{array}{l}\text { Open woodland/field } \\
\text { Rough-textured, arid wooded }\end{array}$ & 5 & 2 & 2 & 6 \\
Open, smooth texture & 5 & & 5 & \\
Vista, not heavily wooded & 12 & & & \\
Forest and forest vista & 5 & & & \\
\hline
\end{tabular}

Wildflower Society group preferred rougher textured scenes, while the student group preferred open woodlands.

A fourth group consisted of five scenes showing relatively smooth ground textures and plenty of open sky (Fig. 4). The three samples did not differ in their preference for this grouping, and for the Australians these scenes were preferred at the same level as the open woodlands (all around 2.9 on average). The Wildflower Society members greatly preferred the rougher textures of the grouping represented in Fig. 3 to the more manipulated, smooth textures represented by Figs. 2 and 4 .

The fifth grouping, based on the American preference ratings, consisted of five scenes of vistas, not including views of heavily wooded areas (Fig. 5, top row). The American students significantly preferred this grouping to the Australians. This grouping was less preferred than forests and vistas of forests (Fig. 1) by each of the three participant samples. $\Lambda t$ the same time, it was preferred to each of the other categories by the two student samples and to the smooth texture, open sky grouping by the Wildflower Society group.

\section{Australian-student-based categories}

Table II shows the correspondence between the American- and Australian-student-based groupings. The two sets of perceptual categories are surprisingly distinct. The most pre- ferred of the Australian-based categories (as with the American-based set) was the most densely forested. The top right scene in Fig. 1 is common to the two sets; the bottom row shows two scenes included in the Australian, but not in the American, category. The Australian-based grouping includes scenes more characteristic of the Western Australian forest. It is hardly surprising that members of the Wildflower Society were significantly more enthusiastic about these scenes than the Australian students, whose preference was greater than the American students. In contrast, the grouping based on the American data consisted of scenes consistently appreciated by all three groups, and these higher preferences were the same for the three samples.

A second Australian-based category showed relatively strong overlap with the Americanbased "open woodland and field" grouping. Seven scenes were common to the two, including the two in the bottom of Fig. 2. In the case of the Australian-based category, the sense of aridity and the relatively coarse texture of the ground plane is more prominent. While for the grouping based on American student preferences the two Australian samples were comparable in their preference, for these more arid scenes the Wildflower Society members expressed greater preference than did the Australian students.

The final category based on the Australian 
student sample included all five of the vista scenes comprising one of the American-based categories, as well as seven additional settings. The scenes in Fig. 5, top row, are common to both these groupings; the bottom row, however, includes scenes included only in the Australian-based category. What seems to characterize the category is a sense of manipulated environments: some depict exotic vegetation (pines); others show large cleared or grazed areas. The manipulation generally gives a greater sense of space, with smoother ground textures. Not surprisingly, these are scenes which are significantly preferred by the student samples as opposed to the more conservation-oriented Wildflower Society members.

\section{DISCUSSION AND CONCLUSIONS}

These results are instructive in two major respects. Some striking differences identified in preferences might be considered to be crosscultural (between the two student samples). Since some of the larger differences are between the two Australian samples, this may be an important sub-cultural dimension. Secondly, important differences occur between perception and preference. Preferences are generally more similar than perceptions. The dimensional solutions based on each of the two student samples suggest different ways of seeing the environment. Thus the use of analytic methods different from those used in the past leads to different insights about cross-cultural and sub-cultural differences.

The three categories based on the Australian-student sample distinguish among three characteristic aspects of Western Australian landscapes: Eucalypt forests, often with strong vertical trunks and grey/green foliage; Australian scrubland, which is quite open and arid; pastoral, grazed and more manipulated spacious areas. For the American students many of these landscapes are "foreign". The basis for the categorization ${ }^{1}$ can hardly be based on characteristic landscapes. The five groupings exemplify the kinds of issues which have consistently emerged in such analyses in previous studies (Kaplan, 1985). Openness and smoothness of ground texture are salient properties of the perceptual process. These qualities inform one as to both visual access and ease of locomotion. Similarly, vistas afford visual access on a larger scale. Finally, trees play an important role in perception of the natural environment. Thus the combination of tree cover and ground texture distinguishes among several of the categories.

The high correlations between sets of preference ratings supports the findings of others, but can be easily misinterpreted. Differences in preferences are perhaps as important as similarities. The deep and divisive conflict among Western Australian groups with respect to the use of exotic vegetation is evident here in the consistent preference differences between the two Australian samples. Schmidt and Kimber (1985) describe the extent of public concern for the conflicting uses of this region. Preference ratings can serve as an important tool to help various citizen groups recognize their differences, as well as their agreements (Hudspeth, 1982).

While preference is affected by familiarity, people do not necessarily prefer what they are familiar with. Doubtless, the Wildflower Society members are no less familiar with pine stands as the students. On the other hand, the overall greater preference for the scenes as a whole on the part of the Australians may well be attributable to familiarity with the local landscape. Preference is also affected by other factors. Scenes consistently highly preferred across all three groups have generic properties that people prefer (Kaplan and Kaplan, 1982). Both "content" themes, i.e. water and trees,

There is no assumption here that the categorization is based on a conscious process. These groupings are derived from preference ratings which are made rapidly and intuitively. 
play a role, as well as informational properties communicated by the organization of the pictured space. In addition, interest and expertise are also important factors which affect preference. In fact, expertise and interest may be as potent in defining sub-cultures as are morc traditional demographic variables.

Different conclusions about similarities and differences in both environmental preference and perception would have resulted if the study had included any two of the three samples. While both Australian and American samples represent "western culture", clear differences exist in the American and the Western Australian landscapes. The fact that the two samples which share the same landscape show major differences in preferences has important implications for public participation and the management of land resources.

\section{ACKNOWLEDGEMENTS}

This study was carried out while the second author was with the Forests Department, Western Australia. D.J. Illingworth's assistance made it possible to collect data at the University of Western Australia. Support from the Urban Forestry Project through Cooperative Agreements 13-655 and 23-84-08, U.S. Forest Service, North Central Forest Experiment Station, to R. Kaplan and S. Kaplan, is also gratefully acknowledged.

\section{REFERENCES}

Anderson, E., 1978. Visual resource assessment: local perceptions of familiar natural environments. Doctoral Dissertation, University of Michigan.

Balling, J.D. and Falk, J.H., 1982. Development of preference for natural environments. Environ. Behav., 14: 5-28.

Buhyoff, G.J., Wellman, J.D., Harvey, H. and Fraser, R.A., 1978. Landscape architects' interpretations of people's landscape preferences. J. Environ. Manage., 6: 255-262.

Buhyoff, G.J., Leuschner, W.A. and Wellman, J.D., 1979. Aesthetic impacts of Southern Pine Beetle damage. J. Environ. Manage., 8: 261-267.

Coughlin, R.E. and Goldstein, K.A., 1970. The extent of agreement among observers on environmental attractive- ness. Regional Science Research Institute, Discussion Paper, Series No. 37, Philadelphia, PA.

Daniel, T.C. and Boster, R.S., 1976. Measuring landscape esthetics: The scenic beauty estimation method. U.S. Forest Service Research Paper RM-167.

Gallagher, T.J., 1977. Visual preference for alternative natural landscapes. Doctoral Dissertation, University of Michigan.

Hammitt, R.E., 1979. Measuring familiarity for natural environments through visual images. Proc. Our National Landscape Conf, U.S. Forest Service, Gen. Iech. Kep. PSW-35, pp. 217-226.

Hudspeth, T.R., 1982. Visual preference as a tool for citizen participation: A case study of urban waterfont revitalization in Burlington, Vermont. Doctoral Dissertation, University of Michigan.

Kaplan, R,, 1973. Predictors of environmental preference: Designers and "Clients". In: W.F.E. Preiser (Editor), Environmental Design Research. Dowden, Hutchinson and Ross, Stroudsburg, PA.

Kaplan, R., 1985. The analysis of perception via preference: a strategy for studying how the environment is experienced. Landscape Plann., 12: 161-176.

Kaplan, R. and Talbot, J.F., 1987. Ethnicity and preference for natural settings: a review and recent findings. Landscape Plann., in press.

Kaplan, S. and Kaplan, R., 1982. Cognition and Environment: Functioning in an Uncertain World. Praeger, New York.

Kulik, J.A., Revelle, W.R. and Kulik, C.-L.C., 1970. Scale construction by hierarchical cluster analysis. University of Michigan, unpublished paper.

Lingoes, J.C., 1972. A general survey of the Guttman-Lingoes nonmetric program series. In: R.N. Shepard, A.K. Romney and S.B. Nerlove (Editors), Multidimensional Scaling. Vol. 1. Seminar Press, New York.

Schmidt, W. and Kimber, P., 1985. Conservation by consensus: The Lane-Poole Jarrah Reserve. Landscape, 1: 19-28.

Schroeder, H.W., 1983. Variations in the perception of urban forest recreation sites. Leisure Sci., 5: 221-230.

Shafer, E.L. and Tooby, M., 1973. Landscape preferences: An international replication. J. Leisure Res., 5: 60-65.

Sonnenfeld, J., 1967. Environmental perception and adaptation level in the Arctic. In: D. Lowenthal (Editor), Environmental Perception and Behavior. Department of Geography, University of Chicago.

Ulrich, R.S., 1983. Aesthetic and affective response to natural environment. In: I. Altman and J.F. Wohlwill (Editors), Bchavior and the Natural Environment. Plenum, New York.

Zube, E.H., 1984. Themes in landscape assessment theory. Landscape J., 3: 104-110.

Zube, E.H. and Mills, L.V., Jr., 1976. Cross-cultural explorations in landscape perception. In: E.H. Zube (Editor), Studies in Landscape Perception. Institute for Man and Environment, University of Massachusetts, Amherst, MA.

Zube, E.H. and Pitt, D.G., 1981. Cross-cultural perceptions of scenic and heritage landscapes. Landscape Plann., 8: $69-87$. 
Zube, E.H., Pitt, D.G. and Anderson, T.W., 1975. Perception and prediction of scenic resource values of the northeast. In: E.H. Zube, R.O. Brush and J.G. Fabos (Editors), Landscape Assessment: Values, Perceptions and Resources. Dowden, Hutchinson and Ross, Stroudsburg, PA.
Zube, E.H., Pitt, D.G. and Evans, G.W., 1983. A lifespan developmental study of landscape assessment. J. Environ. Psychol., 3: 115-128. 